\title{
Gynecomastia and Chest Masculinization: An Updated Comprehensive Reconstructive Algorithm
}

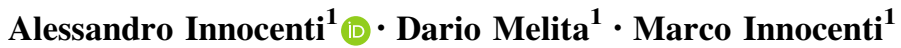

Received: 6 January 2021 / Accepted: 28 March 2021

(C) Springer Science+Business Media, LLC, part of Springer Nature and International Society of Aesthetic Plastic Surgery 2021

\begin{abstract}
Background Gynecomastia is a common finding in males. Clinical aspect varies widely in world populations showing peculiar hallmarks according to different body shapes reflecting personal expectations; therefore, a surgical plan must be tailored on individual basis to all type of patients. Materials and Method A total of 522 patients, treated for bilateral gynecomastia from January 2007 to January 2019, were included and reviewed in this retrospective study. Considering physical status BMI, muscular trophism, hypertrophy of the mammary region, nipple-areola disorder, gland and skin cover consistency, a four-tier classification system has been used to classify the deformity and to assess a surgical plan. In all cases, a subcutaneous mastectomy was performed under direct vision.

Results No recurrence of the deformity was observed as well as major complications such as necrosis, and high level of satisfaction was observed in all groups. No breast cancer was found at the histological examinations Operative time ranged from 25 minutes up to 120 minutes and hospitalization time ranged from 1 to 3 days.

Conclusion Since the physical status is strictly related to the clinical features of the disorder, a comprehensive classification system and a reconstructive algorithm are proposed.

Level of Evidence IV This journal requires that authors assign a level of evidence to each article. For a full description of these Evidence-Based Medicine ratings,
\end{abstract}

Alessandro Innocenti

innocentiplasticsurgery@gmail.com

1 Plastic and Reconstructive Microsurgery, Careggi University Hospital, Viale Giacomo Matteotti 42, 50132 Florence, Italy please refer to the Table of Contents or the online Instructions to Authors www.springer.com/00266

Keywords Gynecomastia - Male breast - Chest masculinization - Surgical algorithm · Gynecomastia classification $\cdot$ Male tuberous breast

\section{Introduction}

Gynecomastia is a benign enlargement of the mammary region, commonly diffused among men, showing peculiar hallmarks according to the body shapes of the patients affected from the disorder [1]. Considering the wide range of population [2, 3], a sensitive discrepancy among expectations is observed, posing a great challenge in aesthetic correction. Its incidence ranges widely in the world population, ranging from 32 to 65 percent [4]. The etiology of gynecomastia is heterogeneous. Although several secondary forms of gynecomastia have been identified, more than $80 \%$ of the disorders are idiopathic and therefore related to a hypersensitivity of the glandular estrogen receptors present in the breast parenchyma [5, 6]. Gynecomastia is considered a psychological threat to normal self-esteem and sexual identity and often patients feel ashamed of their bodies during normal social activities $[7,8]$. Focusing on the breast hypertrophy and the presence of redundant skin, several classifications have been proposed in the literature to address gynecomastia and many surgical techniques have been described for its correction $[9,10]$. However, gynecomastia affects patients with different body shapes: muscular subjects, average physique and overweight patients. In each of these subgroups, peculiar hallmarks, reflecting patients' expectations, can be observed. Since the physical status is strictly related to the 
clinical features of the disorder, a reconstructive comprehensive algorithm, including the rarest forms of gynecomastia, aids in identification of all hallmarks of the clinical status of the deformity and to establish the most appropriate treatment strategy. In this paper, the authors propose a classification system that has enabled the formulation of a surgical plan tailored on individual basis to all type of patients for correction of gynecomastia.

\section{Material and Method}

A total of 522 patients (1044 breast) treated for bilateral gynecomastia by the senior author from January 2007 to January 2019 were included and were reviewed in this retrospective study. Data collected included personal data pre- and post-operative photographs, complications and patients' satisfaction. Only patients with minimum 12-month follow-up were included. Patients were asked to respond pre- and postoperatively to a satisfaction ratings questionnaire suggested in 2009 by Ridha et al. using a 5-point Likert scale (1, very dissatisfied; 2, dissatisfied; 3, neither; 4, satisfied; 5, very satisfied) [11]. Preoperative questionnaire also included the evaluation of the degree of the patients' own perception of the gynecomastia and limitations, if any, to their lifestyle caused by the disorder. Among patients' postoperative satisfaction scoring, chest profile, numbness, symmetry, nipple/areola contouring and scarring were assessed. At the end of every single procedure, an elastic compressive jersey was applied for 3 to 5 days and minimal activity was suggested for the first week.

\section{Classification Schema}

Following parameters have been included to investigate gynecomastia hallmarks: overall physical status (including BMI and muscular trophism), hypertrophy of the mammary region, gland and skin cover consistency and nipple-areola disorder. A four-tier classification system has been used to facilitate the qualification of severity of the deformity.

\section{GROUP I}

It includes subjects with athletic physique, defined muscular body mass, BMI $<25$ and body fat $<9 \%$. Usually, the deformity consists only in a very circumscribed glandular bulk behind the areola covered by a very elastic skin. Among group I, two subgroups are identified: Ia and Ib, showing, respectively, small and large areola.

\section{GROUP II}

It includes patients with average physique and BMI from 18 to 25 . This group presents the most heterogeneous spectrum of clinical degrees but commonly showing a well-defined inframammary fold and the absence of breast ptosis. Two subgroups are identified: IIa and IIb, showing, respectively, firm gland with elastic skin cover and mobile gland with inelastic skin cover. Even if these subjects are not related to high BMI, fat deposits may also be present especially in sub- and supra-axillary zones.

\section{GROUP III}

It includes overweight patients (BMI $>25)$; being related to obesity, in this group fat component is prevalent over the gland. Well-defined inframammary fold, ptosis and a woman-like areola are distinctive hallmarks in this group. Three subgroups are identified:

- Group IIIa: NAC above the inframammary fold

- Group IIIb: NAC below the inframammary fold, moderate breast hypertrophy

- Group IIIc: NAC below the inframammary fold, severe breast hypertrophy

\section{GROUP IV}

Includes gynecomastia with tuberous breast hallmarks: stenotic breast constricted by a fibrous ring at the mammary base, a high inframammary fold and large areola [12-16].

\section{Surgical Technique}

Figure 1 demonstrates the treatment-planning algorithm used in this study. Patients were marked preoperatively in the upright position. Pertinent markings included mid clavicular line, peripheral border of the parenchyma, inframammary fold, supra- and sub-axillary liposuction areas, ideal NAC position. The symmetry of these markings was aided by vertical sternal midline [17]. Five hundred and sixteen patients were performed under local anesthesia. Tumescent solution consists of $10 \mathrm{~mL}$ of lidocaine $2 \%, 20 \mathrm{~mL}$ carbocaine $2 \%, 10 \mathrm{~mL}$ naropine $10 \%, 1$ $\mathrm{mg}$ adrenaline, $100 \mathrm{~mL}$ of saline solution. Six cases underwent general anesthesia because of psychological and intellectual disorders. All enrolled patients underwent surgical adenectomy under direct vision using a scissor trough a periareolar surgical incision. The parenchyma is firstly dissected form its outer surface and then from the pectoralis fascia and then pulled out. Complete en bloc 


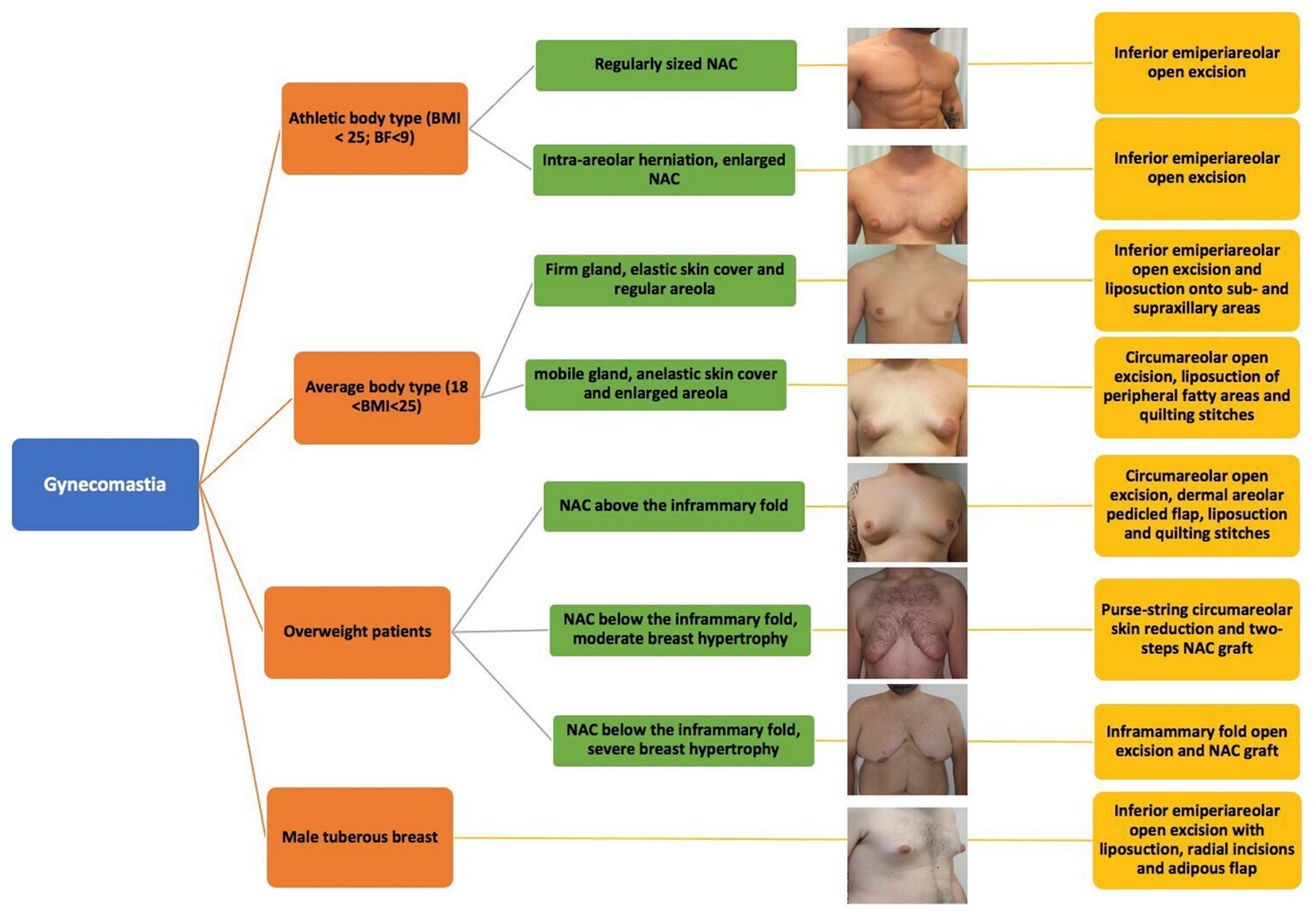

Fig. 1 Classification schema and reconstructive algorithm

excisions of glandular tissue were performed in all cases $[18,19]$.

\section{GROUP I}

Adenectomy is performed through a small incision (ranging from 2 up to $4 \mathrm{~cm}$ in length) located at the inferior border of the areola. Seeking for a maximum definition of the pectoralis major, skin flaps must be thinned as much as possible as well as sub-areolar tissue in order to shrink the areola; obviously, respect of dermal plexus is mandatory in order to avoid necrosis [20,21]. Although fat component is almost absent, to maximize the definition of the inferior lateral border of the pectoralis, subdermal undermining with a cannula can achieve a pleasant skin retraction along the sub-axillary area.

\section{GROUP II}

Both glandular and adipose tissue must be acted by surgical excision and liposuction [22-24]. Subgroup II undergoes adenectomy trough inferiorly bordered areolar access; the thinning of their elastic skin cover ensures a satisfactory extra skin recontouring. In subgroup II b, extra-skin recontouring requires circumareolar approach, wide undermining of skin flap with liposuction of peripheral fatty areas and quilting stiches to recontour the redundant skin [25]. Although extra areolar scars can manage the extra-skin, in these patients a second look should be considered to optimize the final result; thus to maintain the circumareolar approach, limiting extra areolar scars to a small cohort of patients where a crescent aspect of the breast can interfere with final outcome [26].

\section{GROUP III}

Subgroup III a is treated as group II b. Ptotic areola is upward repositioned with a superior dermal pedicle flap $[27,28]$. In subgroup III $b$, redundant skin is managed with purse-string suture while NAC is temporary located in the groin fold. Even if this procedure requires a second step to graft the NAC in the pectoral area, it permits to avoid very visible scars that affect subgroup III c. In subgroup III c, similarly to that used for patients affected from female-tomale gender dysphoria, adenectomy is performed through an incision along the inframammary crease. The previously 
harvested NAC is then grafted at the end of the procedure in the appropriate position after tailoring.

\section{GROUP IV}

In patients suffering from tuberous gynecomastia, the skin is usually in excess compared to the gland. The anchorage of this skin surplus at the underlying fascial thickening forms a well-defined footprint, resembling a female IMF. Because it tends to conserve its memory, this footprint may be very difficult to correct after gland removal, representing a sensitive limitation to the redistribution of the extra skin onto a wider area in the mammary region. Adenectomy, performed through an inferiorly bordered areola incision, remains the milestone in surgical correction, but radial incisions of the fibrous ring could not be sufficient to release the constriction of the lower pole, where a footprint of the inframammary fold may persist. Once the outer surface of the gland is completely dissected from the overlying skin, the gland is vertically split into two and the caudal part of the separated parenchyma is pulled out. The remaining portion of breast tissue remains connected to the pectoralis fascia and it is inset as an advancement flap in the subcutaneous pocket, to realign the stenotic appearance of the pectoral area below the IMF with the rest of the chest profile (Fig. 2).

In the presence of only a persistent intra-areolar herniation of parenchyma overlying a normal masculine pectoral area, only a retro glandular flap is required [29]. Once the posterior surface of the gland bulk is separated from the pectoralis fascia, basing its vascularization on a superficial distal pedicle, a glandular flap was harvested from behind the areola and then inset in a subcutaneous pocket to recontour the pectoralis area below the inferior border of the areola to the rest of the pectoral region (Fig. 3). The use of the flap produces a telescopic realignment of the areola, reducing its prominent aspect, and projects forward the
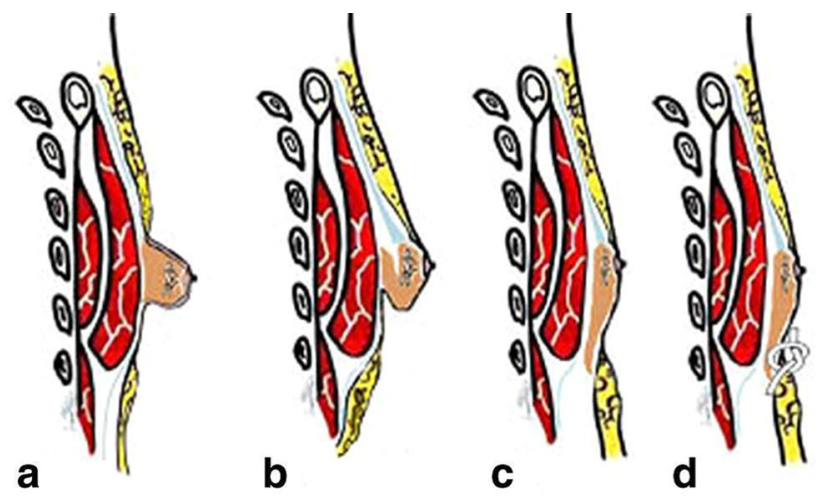

Fig. 3 Surgical technique: a permanent herniation of parenchyma behind the areola; b retro areola distally based flap of parenchyma dissection; c downward flap rotation with a finger glove maneuver; d flap inset, native inframammary fold releasing and chest recontouring

IMF, balancing the difference in contour between the areola and the chest.

\section{Results}

A total of 147 patients belonged to group I, 177 to group II, and 164 to group III and 34 to group IV. Routine laboratory tests did not demonstrate any hematocrit or hemoglobin anomalies, even renal, thyroid, and liver functionality were in range. Ages ranged between 18 and 52 years with an average of 31,4 years. Average follow-up period was 34 months ranging from 12 up to 60 months. Operative time ranged from 25 minutes up to 120 minutes. Hospitalization time ranged from 1 to 3 days.

A total of 298 surgical accesses were located in the inferior part of the areola, a circumareolar approach was performed in 184 cases, whereas vertical or inverted $\mathrm{T}$ incisions, as in standard vertical reduction mammoplasty, were reserved to 29 cases of overweight patients in which the amount of breast tissue was greater than $240 \mathrm{~g}$ and
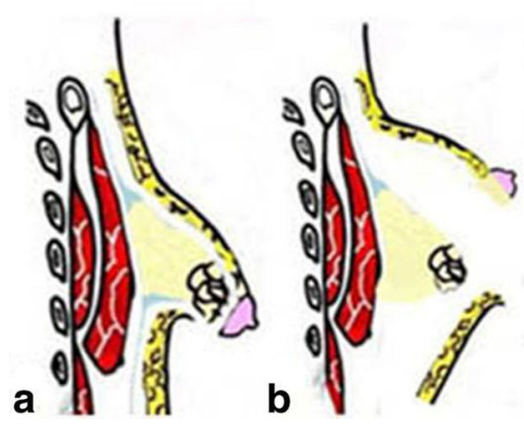

C

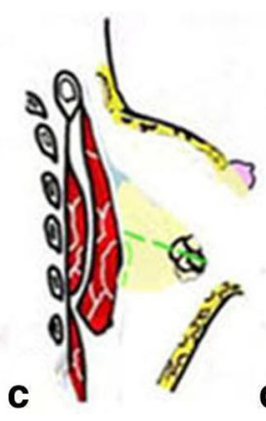

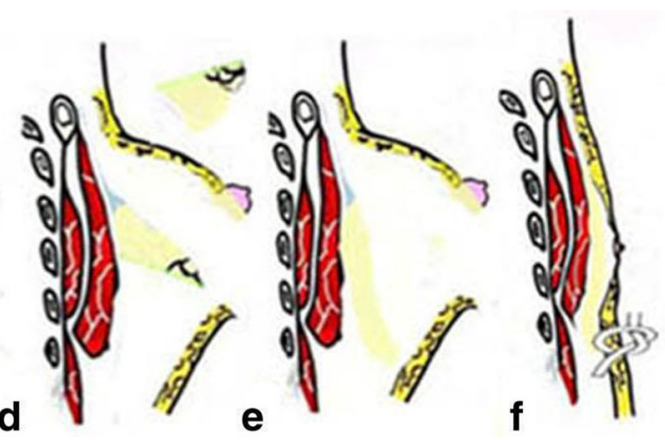

d removal of the extra parenchyma from the caudal part of the gland ; $\mathbf{e}$ and $\mathbf{f}$ parenchyma flap inset and native inframammary fold releasing
Fig. 2 Surgical technique: $\mathbf{a}$ and $\mathbf{b}$ dissection of the outer surface of the parenchyma from the skin flap ; $\mathbf{c}$ vertical split of the gland into two portions to harvest an adipo-glandular flap for IMF release; 
inelastic sagging skin was present. Seven purse-string circumareolar skin reduction and secondary NAC grafting and 4 inframammary fold incision, similar as in female-tomale chest masculinization, have been recorded in group III. Excised glandular tissue weight ranged from 45 to 426 $\mathrm{g}$ per side. No breast cancer was found at the histological examinations. Three high muscle mass patients had a pathological report of atypical intraductal hyperplasia. Recurrences of the disorders have not been observed at all. In 156 of the cases, a drain was placed through the axilla for 12-24 hours [30-33]. In the remaining 366 cases, no drainage was used. Eight hematomas requiring immediate revision of the surgical theatre were reported. Severe bleeding, in a hemophilic patient, was promptly resolved by our hemophilic center. Other hemophilic patients were operated by the authors without any problems. We found 11 seromas limited to overweight patients in whom large amounts of fat were removed. Seromas lasted from minimum 10 up to a maximum of 25 days and have required a weekly percutaneous drainage. Depressions, deforming the contour profile of the mammary region, were visible postoperatively only during muscular contraction in 22 patients belonging to group I. Nine similar irregularities were observed also in group II always visible even without muscular contraction and one in the group IV. Although in overweight patients, depressions have not been observed; in 28 patients, a crescent ptotic tissue at the lower border of the pectoralis muscle was present at the follow-up. Only 11 of these cases required further correction through a secondary vertical approach, whereas the other excluded wider scars. Five minimal surgical scar revisions were reported because of the presence of unpleasant enlarged scars: three in group III and two in group IV.

The main reason for undergoing surgery resulted: in group I, lack of self-confidence because of unsatisfactory contouring of the pectoralis area; in group II and IV, emotional distress due to feminine appearance; and in group III, weight disorder (Fig. 4)

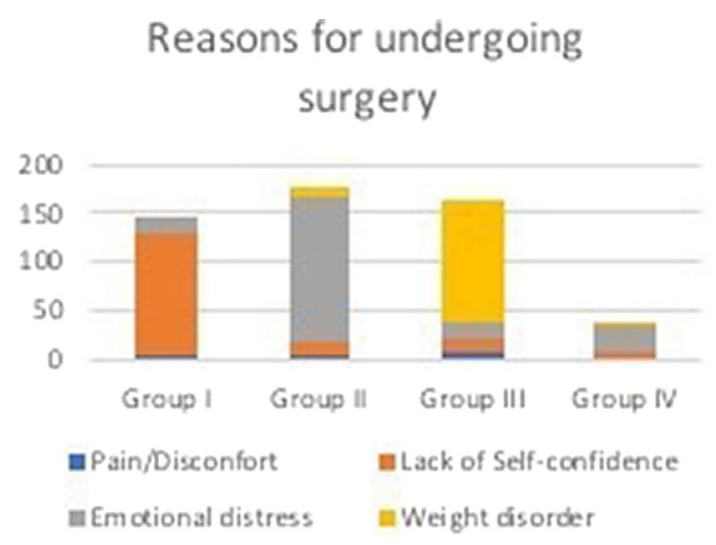

Fig. 4 Emotional distress' causes
The mean Likert score for patients' satisfaction of chest appearance was 1,325 . The mean value among group I was 1,36 ; in group II 0,58 ; in group III 2,12 and in group IV 1,24. Postoperative the mean over all Likert score was 4,33. Data, shown in Fig. 5, reported the higher increase of postoperative satisfaction score in group II. Cases are shown in Figs. 6, 7, 8, 9.

\section{Discussion}

Gynecomastia strongly interferes with patients' psychological wellness. Even in the presence of the minor forms, the affected subjects result very distressed by the malformation, and therefore, chest masculinization is nowadays a very popular surgical procedure [34-38]. Although gynecomastia is a single etiological entity, affecting a wide range of male population distressed differently by the disorder, it should be considered from very different points of views including patients' goals which are often conditioned by lifestyles including fitness addiction and body care [39-41]. All these items play a leading role and they must be strongly considered for a tailored surgical planning; therefore, a comprehensive reconstructive algorithm should be taken into account by surgeons.

In athletic subjects, the low percentage of fatty tissue highlights also small glands, interfering with their physical training purposes. The great attention to the physical appearance renders them very sensitive to the problem $[42,43]$. Although the presence of a large areola worsens their distress highlighting the feminine appearance of the deformity, circumareolar approach should be carefully discussed because it could not offer a real vantage. In fact, even if the interlock suture contrasts the centrifuge forces resulting from the discrepancy between the tailored areola and the outer skin-ring, recurrence of its enlargement can

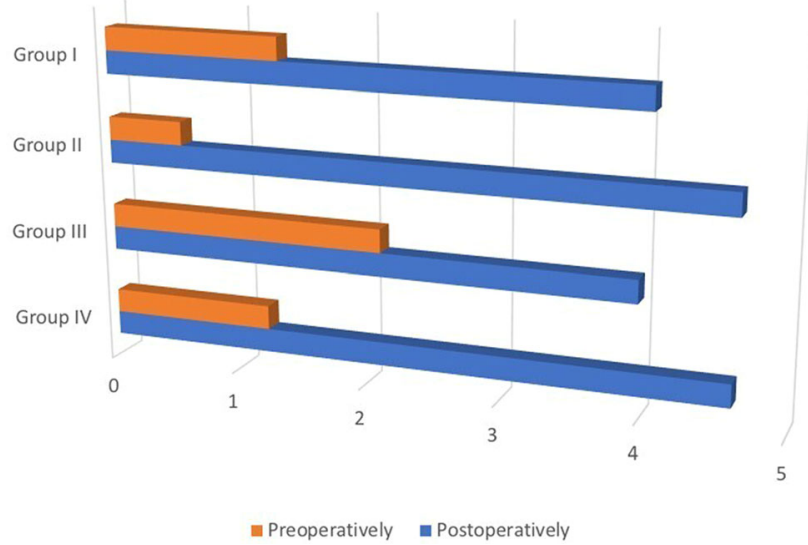

Fig. 5 Analysis of pre- and postoperatory satisfaction with chest appearances using Likert score 


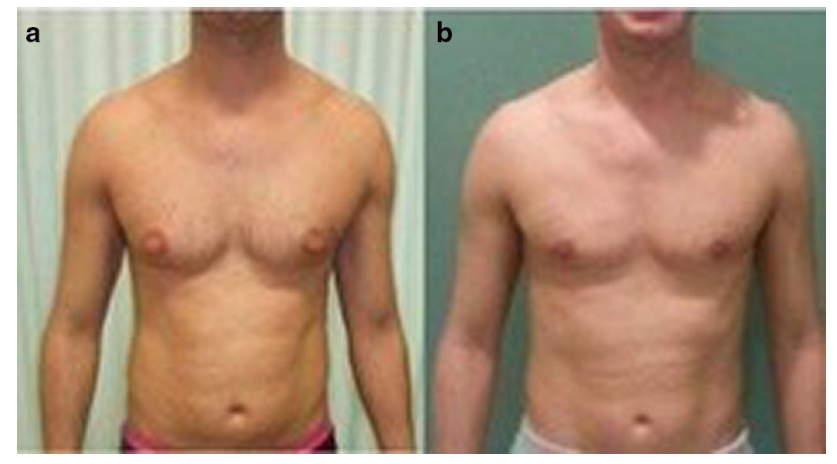

Fig. 6 Case 1: 22-year-old man, classified as type Ib gynecomastia showing muscular physical appearance and enlarged areola. a Preoperative frontal view; b Postoperative frontal view at 6 months. Adenectomy has been performed through inferior emiperiareolar incision. A sensitive thinning of the areola thickness permitted to obtain a significant areola shrinking. 3/0 poliglecaprone interrupted suture and 4/0 poliglecaprone subcuticular suture have been used

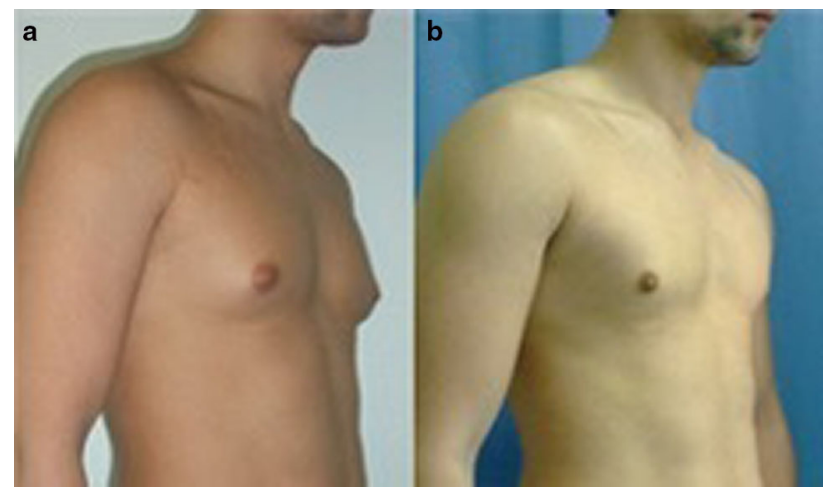

Fig. 7 Case 2: 19-year-old man, classified as type IIa gynecomastia showing firm gland and elastic skin cover, defining a feminine aspect of the chest. a Preoperative lateral view; b 9 months postoperative lateral view shows chest redefinition and areolar shrinking. Adenectomy has been performed through inferior emiperiareolar incision and liposuction which have been performed from the areola incision. Widely undermining of all pectoral region was performed to obtain a satisfactory recontouring of the extra skin. A sensitive thinning of the areola thickness obtained a significant areola shrinking. Skin closure have been performed with $3 / 0$ absorbable interrupted and subcuticular sutures

occur with more visible scars. Average body type patients are not particularly focused on sports habits and do not reserve particular attention to their body fitness appearance; females affected by gender dysphoria suffer from female appearance revealing social limitations, and they require a more masculine aspect of the chest to eliminate social embarrassment improving their own self-esteem. Overweight patients represent the most severe variants [44]. They retain gynecomastia as a weight disorder rather than a female appearance, so that they require a slimmer and more toned aspect. Male tuberous breast deformity, even rarely, might be observed in gynecomastia population and, even if still poorly investigated, it must be included in
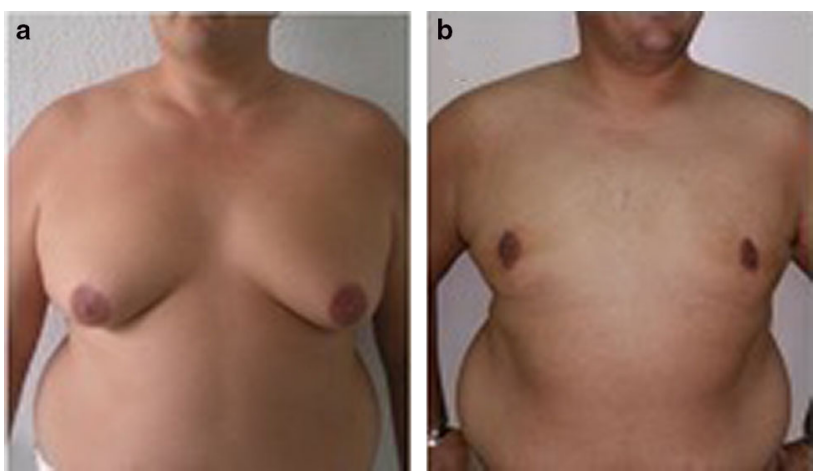

Fig. 8 Case 3: 45-year-old man, classified as type IIIb gynecomastia showing significant female ptosis and woman-like areolas. a Preoperative frontal view; b Postoperative frontal view at 6 months after secondary NAC graft. Redundant skin is managed with $3 / 0$ Goretex ${ }^{\circledR}$ purse-string suture and 4/0 absorbable interrupted suture, while NAC is temporary located in the groin fold. NAC grafting was performed 3 months after the adenectomy
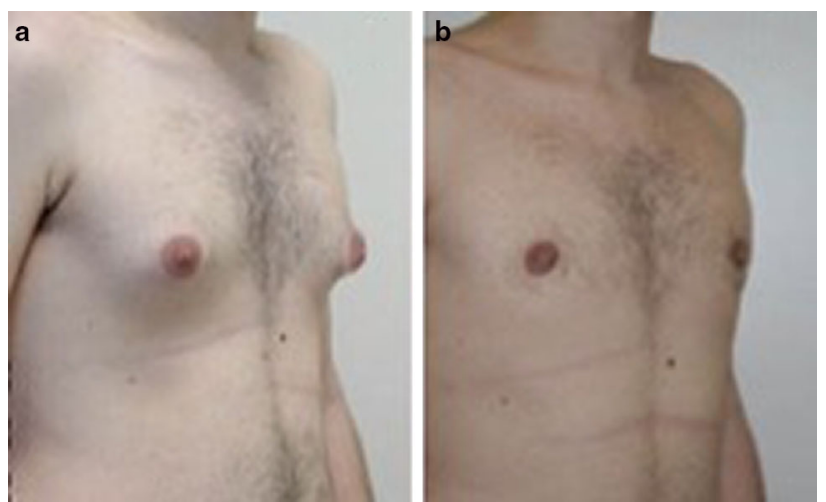

Fig. 9 Case 4: 22-year-old man, classified as type IV gynecomastia showing male tuberous hallmarks; a Preoperative lateral view, b Postoperative lateral view at 14 months postop. Adenectomy has been performed through inferior emiperiareolar incision, with native inframammary sulcus release. To allow a telescopic realignment of areola and a satisfactory recontouring of the retracted footprint of the IMF a pedicled flap was harvested from behind the areola and then inset in a subcutaneous pocket

an algorithm because, showing peculiar anatomical characteristics, its correction could benefit from particular surgical tricks to avoid the persistency of the footprint at the inframammary fold [45].

Although the grade of breast hypertrophy is the main field of interest in gynecomastia correction, the quality of the skin represents a crucial element for surgical strategy. It is not only theoretical, and it must be considered in an algorithm. Thinning of an elastic firm skin flap overlying a compact and solid gland allows minimal areolar scars in extra skin management even in the presence of severe parenchymal hypertrophy rather than a small mobile gland covered by inelastic and atrophic skin, as well as subdermal thinning behind the NAC can shrink the areola $[46,47]$. Obviously, the respect of the dermal plexus is 
mandatory to avoid severe complications [48]. However, in the presence of residual crescent aspect of the skin flap, a purse string second look could be hypothesized to limit the need of extra-areolar scars. Since scarring is one of the most common reasons for claims, it should be limited to the circumareolar area as much as possible because of a favorable color mismatch [49]. Gently management of retractors during the procedure is mandatory to avoid unfavorable scarring and post-surgical hyperpigmentation. In the presence of circumareolar incision, Goretex ${ }^{\circledR}$ pursestring suture and absorbable interrupted sutures help to improve scarring quality and to avoid scar stretching. Moreover, postoperative compression by an elastic jersey is routinely suggested for at least 4 weeks.

Although several closed techniques (such as liposuction, mammotome excision and sharp cutting) [50-55] have been proposed to minimize scarring, subcutaneous mastectomy remains the most common procedure permitting radical adenectomy under direct view, histopathological investigation, extra skin management and accurate hemostasis [56, 57]. Moreover, an accurate complete glandular removal reduces the incidence of recurrence $[58,59]$. Even if endoscopically assisted procedures have been successfully described, requiring specific surgical equipment and learning curve, they result more complex $[60,61]$.

Breast ptosis concept includes areola and parenchyma position in relation to inframammary fold. Usually, this item is referred to feminine breasts, but ptosis can occur even in gynecomastia, but differently from mastopexy, male parenchyma must be removed [62,63]. Therefore, compared to the most popular ptosis classification system, only NAC position has been considered in the proposed algorithm.

\section{Conclusion}

Because dissatisfaction with the result represents one of the most common reason of claims, management of patients' expectation is the key element to achieve a high level of approval as the leading measure of treatment success $[64,65]$. Nomenclature classification and a reconstructive algorithm are important in the preoperative identification of each single element to assess the entity of gynecomastia, to assist in achieving more consistent results.

\section{Declarations}

Conflict of interest The authors declare that they have no conflicts of interest

Human and Animal Rights This article does not contain any studies with human participants or animals performed by any of the authors.
Informed Consent For this type of study, informed consent is not required.

\section{References}

1. Fruhstorfer BH, Malata CM (2003) A systematic approach to the surgical treatment of gynaecomastia. Br J Plast Surg. 56:237-246

2. Zavlin D, Jubbal KT, Friedman JD, Echo A (2017) Complications and outcomes after gynecomastia surgery: analysis of 204 pediatric and 1583 adult cases from a national multi-center database. Aesthetic Plast Surg. 41(4):761-767. https://doi.org/10. 1007/s00266-017-0833-z (Epub 2017 Mar 24 PMID: 28341949)

3. Innocenti A, Ghezzi S, Melita D, Ciancio F, Innocenti M (2018) Comment to: "complications and outcomes after gynecomastia surgery: analysis of 204 pediatric and 1583 adult cases from a national multi-center database." Aesthetic Plast Surg. 42(1):334-335. https://doi.org/10.1007/s00266-017-0989-6 (Epub 2017 Oct 26 PMID: 29075817)

4. Innocenti A, Melita D, Mori F, Ciancio F, Innocenti M (2017) Management of gynecomastia in patients with different body types: considerations on 312 consecutive treated cases. Ann Plast Surg. $\quad 78(5): 492-496 . \quad$ https://doi.org/10.1097/SAP. 0000000000000940.PMID:27805927;PMCID:PMC5400408

5. Wollina U, Goldman A (2011) Minimally invasive esthetic procedures of the male breast. J Cosmet Dermatol. 10(2):150-155. https://doi.org/10.1111/j.1473-2165.2011.00548.x $\quad$ (PMID: 21649820)

6. Cuhaci N, Polat SB, Evranos B, Ersoy R, Cakir B (2014) Gynecomastia: Clinical evaluation and management. Indian $\mathrm{J}$ Endocrinol Metab. 18(2):150-158. https://doi.org/10.4103/22308210.129104.PMID:24741509;PMCID:PMC3987263

7. Choi BS, Lee SR, Byun GY, Hwang SB, Koo BH (2017) The characteristics and short-term surgical outcomes of adolescent gynecomastia. Aesthetic Plast Surg. 41(5):1011-1021. https://doi. org/10.1007/s00266-017-0886-Z (Epub 2017 Apr 27 PMID: 28451801)

8. Innocenti A, Melita D, Ghezzi S, Ciancio F, Innocenti M (2017) Comment to: "the characteristics and short-term surgical outcomes of adolescent gynecomastia." Aesthetic Plast Surg. 41(6):1467-1468. https://doi.org/10.1007/s00266-017-0901-4 (Epub 2017 Jun 7 PMID: 28593489)

9. Waltho D, Hatchell A, Thoma A (2017) Gynecomastia classification for surgical management: a systematic review and novel classification system. Plast Reconstr Surg. 139(3):638e-648e. https://doi.org/10.1097/PRS.0000000000003059 (PMID: 28234829)

10. Ciancio F, Innocenti A, Parisi D, Portincasa A (2017) Gynecomastia classification for surgical management: a systematic review and novel classification system. Plast Reconstr Surg. 140(4):620e-621e. https://doi.org/10.1097/PRS. 0000000000003732 (PMID: 28617739)

11. Ridha $\mathrm{H}$ et al (2009) How happy are patients with their gynaecomastia reduction surgery? J Plast Reconstr Aesthet Surg 62(11):1473-1478

12. Innocenti A (2019) Male tuberous breast: a rare variant of gynecomastia clinical considerations and personal experience: tips and tricks to maximize surgical outcomes. Aesthetic Plast Surg. 43(6):1500-1505. https://doi.org/10.1007/s00266-01901418-1 (Epub 2019 Jun 19. PMID: 31218378)

13. Klinger M, Caviggioli F, Klinger F, Villani F, Arra E, Di Tommaso L (2011) Tuberous breast: Morphological study and overview of a borderline entity. Can J Plast Surg. Summer 
19(2):42-44. https://doi.org/10.1177/229255031101900210 (PMID: 22654530; PMCID: PMC3328117)

14. Godwin Y (2018) Correction of tuberous nipple areolar complex deformity in gynecomastia: the deformity that can get forgotten. Ann Plast Surg. 81(1):3-6. https://doi.org/10.1097/SAP. 0000000000001442 (PMID: 29762454)

15. Innocenti A, Ghezzi S, Innocenti M (2019) Correction of tuberous nipple areolar complex deformity in gynecomastia: the deformity that can get forgotten. Ann Plast Surg. 83(3):367. https://doi.org/10.1097/SAP.0000000000001605 (PMID: 30161048)

16. Innocenti A (2020) Male tuberous breast. Cordova A, Innocenti A, Toia F. Springer International Publishing, Tripoli M. Plastic and cosmetic surgery of the male breast, pp 67-74

17. Innocenti A, Pino D, Buccheri F, Cappello F, Larcher L (2020) Preoperative considerations on the thorax: Anatomy and surgical landmarks. Cordova A, Innocenti A, Toia F. Springer International Publishing, Tripoli M. Plastic and cosmetic surgery of the male breast, pp 11-20

18. Tripathy S, Likhyani A, Sharma R, Sharma RK (2020) Prospective analysis and comparison of periareolar excision (delivery) technique and pull-through technique for the treatment of gynecomastia. Aesthetic Plast Surg. 44(3):653-661. https:// doi.org/10.1007/s00266-020-01618-0 (Epub 2020 Jan 27 PMID: 31989232)

19. Melita D, Innocenti A (2020) Prospective analysis and comparison of periareolar excision (delivery) and pull-through technique for the treatment of gynecomastia. Aesthetic Plast Surg. 44(3):1089-1090. https://doi.org/10.1007/s00266-020-01676-4 (Epub 2020 Mar 17 PMID: 32185498)

20. Keskin M, Sutcu M, Hanci M, Cigsar B (2017) Reduction of the areolar diameter after ultrasound-assisted liposuction for gynecomastia. Ann Plast Surg. 79(2):135-138. https://doi.org/10. 1097/SAP.0000000000000994 (PMID: 28252545)

21. Innocenti A, Mori F, Melita D, Innocenti M, Ciancio F (2018) Discussion on "reduction of the areolar diameter after ultrasoundassisted liposuction for gynecomastia." Ann Plast Surg. 80(2):193. https://doi.org/10.1097/SAP.0000000000001163 (PMID: 28650407)

22. Kim DH, Byun IH, Lee WJ, Rah DK, Kim JY, Lee DW (2016) Surgical management of gynecomastia: subcutaneous mastectomy and liposuction. Aesthetic Plast Surg. 40(6):877-884. https://doi.org/10.1007/s00266-016-0705-y (Epub 2016 Sep 27 PMID: 27679453)

23. Innocenti A, Ciancio F, Portincasa A, Parisi D (2017) Discussion: surgical management of gynecomastia-subcutaneous mastectomy and liposuction. Aesthetic Plast Surg. 41(4):983-984. https://doi. org/10.1007/s00266-017-0811-5 (Epub 2017 Feb 15 PMID: 28204929)

24. Walden JL, Schmid RP, Blackwell SJ (2004) Cross-chest lipoplasty and surgical excision for gynecomastia: a 10-year experience. Aesthet Surg J. 24(3):216-223. https://doi.org/10.1016/j. asj.2004.03.005 (PMID: 19336159)

25. Esme DL, Beekman WH, Hage JJ, Nipshagen MD (2007) Combined use of ultrasonic-assisted liposuction and semicircular periareolar incision for the treatment of gynecomastia. Ann Plast Surg. 59(6):629-634. https://doi.org/10.1097/SAP. 0b013e318038f762 (PMID: 18046142)

26. Innocenti A, Melita D, Mori F, Ciancio F, Innocenti M (2017) Comment to "postero-inferior pedicle surgical technique for the treatment of grade iii gynecomastia." Aesthetic Plast Surg. 41(3):747-748. https://doi.org/10.1007/s00266-017-0849-4 (Epub 2017 Apr 3 PMID: 28374294)

27. Ibrahiem SM (2016) Severe gynecomastia: new technique using superior pedicle nac flap through a circumareolar approach. Ann
Plast Surg. 76(6):645-651. https://doi.org/10.1097/SAP. 000000000000229 (PMID: 25003440)

28. Haddad Filho D, Arruda RG, Alonso N (2006) Treatment of severe gynecomastia (Grade III) by resection of periareolar skin. Aesthet Surg J 26(6):669-673. https://doi.org/10.1016/j.asj.2006. 10.009 (PMID: 19338957)

29. Innocenti A, Innocenti M (2015) Retro-areola distally based flap in the management of the full expression of tuberous breast: a simple strategy to resolve a weak point of the deformity. Aesthetic Plast Surg. 39(5):700-705. https://doi.org/10.1007/s00266015-0539-z (Epub 2015 Aug 15 PMID: 26275562)

30. Innocenti A, Serena G, Innocenti M (2020) External quilting: new technique to avoid haematoma in gynaecomastia surgery. Aesthetic Plast Surg. https://doi.org/10.1007/s00266-020-01734-x (Epub ahead of print. PMID: 32333029)

31. Chao JW, Raveendran JA, Maly C, Rogers G, Boyajian M, Oh AK (2017) Closed-suction drains after subcutaneous mastectomy for gynecomastia: do they reduce complications? Aesthetic Plast Surg. 41(6):1291-1294. https://doi.org/10.1007/s00266-0170959-z (Epub 2017 Aug 25 PMID: 28842781)

32. Innocenti A, Melita D, Ghezzi S (2019) Closed-suction drains after subcutaneous mastectomy for gynecomastia: do they reduce complications? Aesthetic Plast Surg. 43(4):1124-1125. https:// doi.org/10.1007/s00266-017-1060-3 (Epub 2018 Jan 4 PMID: 29302730)

33. Innocenti A, Melita D, Re IM (2018) A novel method to insert drain atraumatically after liposuction in gynecomastia. Indian $\mathrm{J}$ Plast Surg 51(3):342-343. https://doi.org/10.4103/ijps.IJPS_106_ 18 (PMID: 30983743; PMCID: PMC6440363)

34. Petty PM, Solomon M, Buchel EW, Tran NV (2010) Gynecomastia: evolving paradigm of management and comparison of techniques. Plast Reconstr Surg. 125(5):1301-1308. https://doi. org/10.1097/PRS.0b013e3181d62962 (PMID: 20440151)

35. Lee SR, Lee SG, Byun GY, Kim MJ, Koo BH (2018) Clinical characteristics of asymmetric bilateral gynecomastia: suggestion of desirable surgical method based on a single-institution experience. Aesthetic Plast Surg. 42(3):708-715. https://doi.org/10. 1007/s00266-018-1102-5 (Epub 2018 Feb 20 PMID: 29464386)

36. Innocenti A, Ghezzi S, Melita D, Innocenti M (2018) Clinical characteristics of asymmetric bilateral gynecomastia: suggestion of desirable surgical method based on a single-institution experience. Aesthetic Plast Surg. 42(6):1716-1717. https://doi.org/10. 1007/s00266-018-1161-7 (Epub 2018 Aug 9 PMID: 30094549)

37. Cardenas-Camarena L, Dorado C, Guerrero MT, Nava R (2017) Surgical masculinization of the breast: clinical classification and surgical procedures. Aesthetic Plast Surg. 41(3):507-516. https:// doi.org/10.1007/s00266-016-0731-9 (Epub 2017 Mar 24 PMID: 28341946)

38. Innocenti A, Ghezzi S, Melita D, Innocenti M (2017) Comment on: "surgical masculinization of the breast: clinical classification and surgical procedures." Aesthetic Plast Surg. 41(6):1475-1476. https://doi.org/10.1007/s00266-017-0925-9 (Epub 2017 Jun 29 PMID: 28664304)

39. Fricke A, Lehner GM, Stark GB, Penna V (2017) Long-term follow-up of recurrence and patient satisfaction after surgical treatment of gynecomastia. Aesthetic Plast Surg. 41(3):491-498. https://doi.org/10.1007/s00266-017-0827-x (Epub 2017 Mar 9 PMID: 28280898)

40. Innocenti A, Melita D, Ciancio F, Innocenti M (2017) Discussion: "long-term follow-up of recurrence and patient satisfaction after surgical treatment of gynecomastia." Aesthetic Plast Surg. 41(5):1242-1243. https://doi.org/10.1007/s00266-017-0866-3 (Epub 2017 Apr 3 PMID: 28374297)

41. Barone M, Cogliandro A, Tsangaris E, Salzillo R, Morelli Coppola M, Ciarrocchi S, Brunetti B, Tenna S, Tambone V, Persichetti P (2018) Treatment of severe gynecomastia after massive 
weight loss: analysis of long-term outcomes measured with the italian version of the BODY-Q. Aesthetic Plast Surg. 42(6):1506-1518. https://doi.org/10.1007/s00266-018-1232-9 (Epub 2018 Sep 26 PMID: 30259165)

42. Aiache AE (1989) Surgical treatment of gynecomastia in the body builder. Plast Reconstr Surg. 83(1):61-66. https://doi.org/ 10.1097/00006534-198901000-00011 (PMID: 2909079)

43. Blau M, Hazani R (2015) Correction of gynecomastia in body builders and patients with good physique. Plast Reconstr Surg. 135(2):425-432. $\quad$ https://doi.org/10.1097/PRS. 0000000000000887 (PMID: 25626789)

44. Ward CM, Khalid K (1989) Surgical treatment of grade III gynaecomastia. Ann R Coll Surg Engl. 71(4):226-228

45. Innocenti A, Innocenti M, Mori F, Melita D, Ciancio F, Cordova A (2018) Tuberous breast: past, present, and future: personal classification, treatment, and surgical outcomes. Ann Plast Surg. 80(2):104-108. https://doi.org/10.1097/SAP.0000000000001200 (PMID: 28885315)

46. Pfeiler PP, Luketina R, Dastagir K, Vogt PM, Mett TR, Kaltenborn A, Könneker S (2020) Expected reduction of the nippleareolar complex over time after treatment of gynecomastia with ultrasound-assisted liposuction mastectomy compared to subcutaneous mastectomy alone. Aesthetic Plast Surg. https://doi.org/ 10.1007/s00266-020-02029-x

47. Innocenti A, Melita D (2020) Expected reduction of the nippleareolar complex over time after treatment of gynecomastia with ultrasound-assisted liposuction mastectomy compared to subcutaneous mastectomy alone. Aesthetic Plast Surg. https://doi.org/ 10.1007/s00266-020-02052-y

48. Özalp B, Berköz Ö, Aydınol M (2018) Is the transposition of the nipple-areolar complex necessary in Simon grade $2 b$ gynecomastia operations using suction-assisted liposuction? J Plast Surg Hand Surg. 52(1):7-13. https://doi.org/10.1080/2000656X.2017. 1313260 (Epub 2017 May 4 PMID: 28471290)

49. Innocenti, A., Ghezzi, S, Melita, D. (2020). Commentary on "Surgical treatment of gynaecomastia: a standard of care in plastic surgery" by Tobias R. Mett, Peter P. Pfeiler, Rosalia Luketina, Alperen S. Bingöl, Nicco Krezdorn \& Peter M. Vogt. Eur J Plast Surg43, 687-688 https://doi.org/10.1007/s00238020-01721-0

50. Apesos J, Chami R (1991) Functional applications of suctionassisted lipectomy: a new treatment for old disorders. Aesthetic Plast Surg. 15(1):73-79. https://doi.org/10.1007/BF02273837

51. Stark GB, Grandel S, Spilker G (1992) Tissue suction of the male and female breast. Aesthetic Plast Surg. 16(4):317-324. https:// doi.org/10.1007/BF01570694

52. Qu S, Zhang W, Li S, He W, Lu R, Zhang Q, Zhang J, Wang N (2020) The vacuum-assisted breast biopsy system is an effective strategy for the treatment of gynecomastia. Aesthetic Plast Surg. https://doi.org/10.1007/s00266-020-01931-8

53. Benito-Ruiz J, Raigosa M, Manzano M, Salvador L (2009) Assessment of a suction-assisted cartilage shaver plus liposuction for the treatment of gynecomastia. Aesthet Surg J. 29(4):302-309. https://doi.org/10.1016/j.asj.2009.02.020

54. Sim N, Tan G, Tan BK, Goh T (2020) Review of the microdebrider excision and liposuction technique (MELT) for the treatment of gynecomastia. J Plast Reconstr Aesthet Surg. 73(2):303-312. https://doi.org/10.1016/j.bjps.2019.09.003 (Epub 2019 Sep 24 PMID: 31672463)
55. Akhtar A, Eitezaz F, Rashid M, Khan I, Malik SA (2019) Liposuction in gynecomastia: an assessment of the suction-assisted arthroscopic shaver versus open disc excision techniques. Cureus. 11(10):e5897. https://doi.org/10.7759/cureus.5897. PMID:31772867;PMCID:PMC6839758

56. Innocenti A, Ciancio F, Francesco M, Melita D, Innocenti M (2017) Comment to "no-drain single incision liposuction pullthrough technique for gynecomastia." Aesthetic Plast Surg. 41(4):990-991. https://doi.org/10.1007/s00266-017-0821-3 (Epub 2017 Feb 15 PMID: 28204934)

57. Innocenti A, Ciancio F, Parisi D, Portincasa A, Melita D, Innocenti M (2017) Comment to "orange peel excision of gland: a novel surgical technique for treatment of gynecomastia." Ann Plast Surg. 79(3):326. https://doi.org/10.1097/SAP. 000000000001126 (PMID: 28795985)

58. Abdelrahman I, Steinvall I, Mossaad B, Sjoberg F, Elmasry M (2018) Evaluation of glandular liposculpture as a single treatment for grades I and II gynaecomastia. Aesthetic Plast Surg. 42(5):1222-1230. https://doi.org/10.1007/s00266-018-1118-x

59. Innocenti A, Melita D, Innocenti M (2018) Evaluation of glandular liposculpture as a single treatment for grades I and II gynecomastia. Aesthetic Plast Surg. 42(6):1707-1708. https://doi. org/10.1007/s00266-018-1156-4 (Epub 2018 Jun 4 PMID: 29869229)

60. Cao H, Yang ZX, Sun YH, Wu HR, Jiang GQ (2013) Endoscopic subcutaneous mastectomy: a novel and effective treatment for gynecomastia. Exp Ther Med. 5(6):1683-1686. https://doi.org/ 10.3892/etm.2013.1032

61. Jian C, Wu L, Lin L, Liu W, Zheng Z, Yang C (2020) Single-port endoscopic mastectomy via the lateral chest approach for the treatment of grade II gynecomastia. Medicine (Baltimore) 99(22):e20100. https://doi.org/10.1097/MD.0000000000020100 (PMID: 32481376)

62. Diyarbakirlioglu M, Ercan A, Dogan Y (2020) Correction of high-grade pseudogynecomastia after massive weight loss: modified inferior dermoglandular pedicled transverse scar reduction. Aesthetic Plast Surg. 44(2):435-441. https://doi.org/ 10.1007/s00266-019-01477-4 (Epub 2019 Aug 26 PMID: 31451852)

63. Innocenti A, Ghezzi S (2019) Correction of high-grade pseudogynecomastia after massive weight loss: modified inferior dermoglandular pedicled transverse scar reduction. Aesthetic Plast Surg. https://doi.org/10.1007/s00266-019-01509-z

64. Innocenti A, Melita D, Mori F, Innocenti M, Ciancio F (2018) Discussion on "gynecomastia surgery-impact on life quality: a prospective case-control study." Ann Plast Surg. 80(2):193-194. https://doi.org/10.1097/SAP.0000000000001172 29319580)

65. Kasielska-Trojan A, Antoszewski B (2017) Gynecomastia surgery-impact on life quality: a prospective case-control study. Ann Plast Surg. 78(3):264-268. https://doi.org/10.1097/SAP. 0000000000000860 (PMID: 27404477)

Publisher's Note Springer Nature remains neutral with regard to jurisdictional claims in published maps and institutional affiliations. 